\title{
In situ forming hydrogels based on polyethylene glycol itaconate for tissue engineering application
}

\author{
MEHRNOOSH HASAN SHAHRIARI ${ }^{1}$, MOHAMMAD ALI SHOKRGOZAR ${ }^{2, *}$, \\ SHAHIN BONAKDAR ${ }^{1,2}$, FARZAD YOUSEFI ${ }^{2}$, BABAK NEGAHDARI ${ }^{3}$ and HAMID YEGANEH ${ }^{4}$ \\ ${ }^{1}$ Department of Biomaterials, Faculty of Biomedical Engineering, Amirkabir University of Technology, \\ P.O. Box 15875-4413, Tehran, Iran \\ ${ }^{2}$ National Cell Bank Department, Pasteur Institute of Iran, P.O. Box: 1316943551, Tehran, Iran \\ ${ }^{3}$ Advanced Technologies in Medicine, Tehran University of Medical Science, P.O. Box 4155-6447, Tehran, \\ Iran \\ ${ }^{4}$ Polyurethane Department, Iran Polymer and Petrochemical Institute, P.O. Box 14965-115, Tehran, Iran \\ *Author for correspondence (mashokrgozar@ pasteur.ac.ir)
}

MS received 6 June 2018; accepted 15 December 2018; published online 14 June 2019

\begin{abstract}
Novel strategies have been proposed to enhance the quality of surgery by scheming noninvasive methods. For this reason, photo-curable in situ forming hydrogels have been well developed during advancements in the regenerative medicine. In this study, polyethylene glycol itaconate (PEGI) was synthesized by reacting polyethylene glycol (PEG) with different molecular weights (1000, 4000 and $\left.8000 \mathrm{~g} \mathrm{~mol}^{-1}\right)$ and itaconyl chloride. The synthesized PEGIs were fully characterized and employed as a macromonomer for the preparation of in situ forming hydrogels using a combination of camphorquinone and dimethylaminoethyl methacrylate as a reactive photoinitiator system, and hydroxyethyl methacrylate as a reactive diluent. The physical properties of the hydrogels including gel yield, equilibrium swelling and compressive strength were determined. The hydrogel based on PEG 4000 with a gel yield of $86 \%$, a water uptake of $103 \%$, a compressive modulus of 11.2 $\mathrm{MPa}$, an elongation at break of $9 \%$ and a curing time of 4 min was selected for the encapsulation of rabbit articular chondrocyte cells. The cytocompatibility of the in situ formed hydrogels was evaluated using 3[4,5-dimethylthiazol-2-yl]2,5-diphenyltetrazolium bromide, live-dead fluorescence assays and optical microscopy observations. Glycosaminoglycans were quantified by dimethylmethylene blue staining from the encapsulated chondrocytes after 14 days. The proposed in situ forming hydrogel can be considered as an injectable and photocurable carrier for cell delivery in cartilage tissue engineering.
\end{abstract}

Keywords. Polyethylene glycol itaconate; chondrocyte; in situ forming; hydrogel; tissue engineering.

\section{Introduction}

Various therapeutic approaches have been explored for tissue regeneration by using different kinds of biomaterials. Among all, the most favourable one is that requires the least possible invasiveness for surgery [1,2]. In some cases, the defect site requires filling that injection of a biocompatible in situ curable substance can be an ideal solution to meet these needs [3]. These structures also provide additional advantages, including exactly filling the defect with no supplemental shaping and enhancement in adjacent tissue attachment or mechanical interlocking [4,5]. Hydrogels have been the material of choice for many applications in regenerative medicine due to their desirable physical and biological characteristics [6,7]. Polyethylene glycol (PEG) has been extensively investigated for use in the preparation of hydrogels due to its availability, simplicity in structure and ability for modifications $[8,9]$. Moreover, this synthetic polymer can be functionalized to produce three-dimensional (3D) networks [10,11]. One way is to conjugate unsaturated groups such as double bond to the
PEG structure $[12,13]$. By applying suitable polymerization conditions on the embedded double bond, simultaneous polymerization and 3D network formation as well as encapsulation of cells or bioactive agents can be performed [14]. Among different polymerization strategies, photopolymerization has attracted much attention. Nowadays, this method has a wide range of biomedical applications such as dental restoration, implant fixation and in situ formation of carriers for drug delivery or cell transplantation [4,15-17].

The camphorquinone (CQ)/tertiary amine photoinitiation system is widely used to prepare in situ forming structures for the applications such as dental restorative resins [1821]. The light curing mechanism of the $\mathrm{CQ} /$ amine system has been described previously by Teshima et al [22]. This process is triggered by the absorption of visible light, excitation of CQ and production of free radicals through the abstraction of a hydrogen atom from the tertiary amine. These amine primary radicals attack the carbon double bonds on the main chains and provide free sites for further crosslinking reactions. 
Unsaturated functional groups, such as maleimides, acrylates or fumarate, can be utilized for the introduction of double bonds to PEG chains [23-27]. Itaconic acid with a carbon-carbon double bond $(\mathrm{C}=\mathrm{C})$ within its side chain may become a choice for the PEG functionalization in light curing application. The copolymers of PEG and itaconic acid were recently suggested for drug delivery application [28,29]. In our previous study, polyesterification of low molecular weight polycaprolactone diols was successfully performed with itaconyl chloride (IC) [30]. This paper reports on the design and synthesis of light-curable hydrogels based on PEG itaconate (PEGI). The physical-chemical characteristics and cytotoxicity of these compositions were evaluated for tissue engineering application.

\section{Experimental}

\subsection{Materials and methods}

PEG with different molecular weights $(1000,4000$ and $8000 \mathrm{~g} \mathrm{~mol}^{-1}$ ), IC, $N$-vinylpyrrolidone, toluene, propylene oxide, methylene chloride and diethyl ether were purchased from Merck (Germany). Hydroxyethyl methacrylate (HEMA), dimethylaminoethyl methacrylate (DMAEMA) and CQ were purchased from Sigma-Aldrich (USA).

\subsection{Synthesis of PEGI}

PEG was pre-dried in a vacuum oven at $70^{\circ} \mathrm{C}$ for $24 \mathrm{~h}$ and then dried via azeotropic distillation using dried toluene under a nitrogen atmosphere before use. A dark three-neck roundbottom flask equipped with a nitrogen inlet, a thermometer and an ice bath was charged with dried PEG $(10 \mathrm{mmol})$, propylene oxide $(25 \mathrm{mmol})$ and dried methylene chloride $(20 \mathrm{ml})$. IC (10 mmol) dissolved in dried methylene chloride $(10 \mathrm{ml})$ was added drop-wisely to the flask over $3 \mathrm{~h}$. After this, the reaction mixture was stirred at room temperature for $48 \mathrm{~h}$ under a nitrogen atmosphere. Finally, methylene chloride was removed in a rotatory vacuum evaporator and the residue was precipitated with diethyl ether. The obtained PEGI was washed twice with diethyl ether and dried in a vacuum oven at room temperature for $24 \mathrm{~h}$.

\subsection{Hydrogel preparation}

A solution of PEGI ( $1 \mathrm{~g})$ in Dulbecco's modified Eagle's medium (DMEM, Gibco, Scotland, $1 \mathrm{ml}$ ) was prepared. Specified amounts of CQ and DMAEMA were also dissolved in HEMA as shown in table 1. The curing process was initiated by the irradiation of CQ-DMAEMA-HEMA solution with blue light (Litex 695 LED curing light, intensity of $1200 \mathrm{~mW} \mathrm{~cm}^{-2}, \lambda_{\max }$ of $470 \mathrm{~nm}$ ) for $2 \mathrm{~min}$. Then, PEGI solution was added, the mixture was irradiated again by blue light for $6 \mathrm{~min}$.
Table 1. The formulations used for the preparation of hydrogels.

\begin{tabular}{lcccc}
\hline Hydrogel & PEGI & HEMA $(\mathrm{ml})$ & CQ $(\mathrm{mg})$ & $\begin{array}{c}\text { DMAEMA } \\
(\mu \mathrm{l})\end{array}$ \\
\hline H1 & PEGI1000 & 1 & 2.5 & 2.5 \\
H2 & PEGI1000 & 1 & 5 & 5 \\
H3 & PEGI1000 & 1 & 10 & 10 \\
H4 & PEGI4000 & 1 & 2.5 & 2.5 \\
H5 & PEGI4000 & 1 & 5 & 5 \\
H6 & PEGI4000 & 1 & 10 & 10 \\
H7 & PEGI8000 & 1 & 2.5 & 2.5 \\
H8 & PEGI8000 & 1 & 5 & 5 \\
H9 & PEGI8000 & 1 & 10 & 10 \\
H10 & - & 1 & 2.5 & 2.5 \\
H11 & - & 1 & 5 & 5 \\
H12 & - & 1 & 10 & 10 \\
H13 & PEGI4000 & 0.5 & 5 & 5 \\
H14 & PEGI4000 & 2 & 5 & 5 \\
\hline
\end{tabular}

\subsection{Instruments}

Gel permeation chromatography (Agilent 1100, PLgel $10 \mu \mathrm{m}$ ) was employed to determine the molecular mass of the synthesized PEGI using tetrahydrofuran as the eluent with a rate of $1 \mathrm{ml} \mathrm{min}{ }^{-1}$. Fourier transformed infrared (FTIR) spectroscopy was performed on a Nicolet spectrometer (model 6700 ) over the wavenumber of $400-4000 \mathrm{~cm}^{-1}$ at a resolution of $2 \mathrm{~cm}^{-1}$ using $\mathrm{KBr}$ pellets. Nuclear magnetic resonance (NMR) spectra were recorded on a Bruker apparatus (model AMX-300).

\subsection{Methods}

The gelation time of the hydrogels was measured via the test tube inverting method [31] at $25^{\circ} \mathrm{C}$ in a water bath. For this purpose, a test tube containing $1 \mathrm{ml}$ of each formulation was irradiated and the fluidity was observed by tilting the tube every $30 \mathrm{~s}$. The time of ceasing the fluidity was recorded as the gelation time.

To determine the gel yield of the prepared hydrogels, samples were soaked initially in water at $50^{\circ} \mathrm{C}$ for $20 \mathrm{~min}$ and then in phosphate buffer saline (PBS) at $25^{\circ} \mathrm{C}$ for $24 \mathrm{~h}$ to remove non-reacted substances. The specimens were then dried in a vacuum oven to reach a constant weight. Gel yield (\%) was calculated based on the weights of the dried sample and the mass of initial monomers (PEGI and HEMA):

$$
\text { Gel yield }=\frac{W_{\text {dried sample }}}{W_{\text {initial monomers }}} \times 100
$$

Water uptake of the prepared hydrogels was determined according to ASTM D570 via immersing samples in PBS at $37^{\circ} \mathrm{C}$ and weighing regularly at different time intervals to obtain a constant weight. Water uptake was calculated 
according to the following equation:

$$
\text { Water uptake }=\frac{W_{\text {wet sample }}-W_{\text {initial mass }}}{W_{\text {initial mass }}} \times 100
$$

In order to assess the percentage of degradation, the samples were immersed in $\mathrm{PBS}$ at $37^{\circ} \mathrm{C}$ for 3 months and every three days, medium was replaced with fresh PBS. At the end of the experiment, the samples were soaked in $\mathrm{PBS}$ at $25^{\circ} \mathrm{C}$ for $24 \mathrm{~h}$ and dried in a vacuum oven.

$$
\begin{aligned}
\text { Gel yield after } 3 \text { months }= & \frac{W_{\text {after } 3 \text { months }}}{W_{\text {initial monomers }}} \times 100 \\
\text { Degradation after } 3 \text { months } & =\text { Gel yield } 24 \mathrm{~h} \\
& - \text { Gel yield } 3 \text { months. }
\end{aligned}
$$

\subsection{Chondrocyte isolation}

Rabbit articular (white New Zealand) cartilage slices were isolated from lateral femoral condyle, predigested with trypsin $(0.25 \%$, Sigma-Aldrich, USA) for $1 \mathrm{~h}$ and digested with collagenase type II $\left(0.08 \mathrm{mg} \mathrm{ml}^{-1}\right.$, Sigma-Aldrich, USA) for $12 \mathrm{~h}$ at $37^{\circ} \mathrm{C}$ [32]. The cells were transferred to DMEM/Ham's F12 culture medium supplemented with $10 \%$ fetal calf serum (Nanobioarray, Iran).

\subsection{Cell encapsulation}

PEGI solution was prepared in DMEM/Ham's F12 culture medium and sterilized by a filter $(0.4 \mu \mathrm{m})$. Cells $\left(3 \times 10^{5}\right)$ suspended in the culture medium was added to the PEGI solution. HEMA-CQ-DMAEMA solution was separately prepared and irradiated by blue light for $2 \mathrm{~min}$ in order to activate the curing process. Then, PEGI-cell solution was added and the mixture was irradiated again by blue light for $6 \mathrm{~min}$ to fulfil the curing process. Finally, the culture medium was added to the cell loaded hydrogels following the incubation at $37^{\circ} \mathrm{C}$ in a humidified atmosphere with $5 \% \mathrm{CO}_{2}$.

The fluorescent dead-live procedure was performed on encapsulated chondrocytes using propidium iodide (PI, Sigma-Aldrich, USA, $750 \mu \mathrm{M}$ )-acridine orange (AO, SigmaAldrich, USA, $670 \mu \mathrm{M}$ ) double staining [31]. Culture medium and dimethyl sulphoxide (Sigma-Aldrich, USA, 10\%) were used as negative and positive controls, respectively.

The cells were also fixed by Karnovsky fixation solution and dehydrated in graded alcohols according to a previously reported procedure [32]. The specimens were sputter-coated with gold and viewed by scanning electron microscopy (SEM, Tescan VegaII, Czech).

\subsection{Agar diffusion cytotoxicity evaluation}

Cells were seeded at a density of $5 \times 10^{3}$ cell per well in 24 well plates and incubated at $37^{\circ} \mathrm{C}$ for $24 \mathrm{~h}$. A solution of agar in deionized water $(1 \%)$ was autoclaved and added to each well $(250 \mu 1)$ to cover the cells. Subsequently, cylindrical hydrogels (diameter of $4 \mathrm{~mm}$ and length of $8 \mathrm{~mm}$ ) were placed on the solidified agar following the addition of culture medium and incubation at $37^{\circ} \mathrm{C}$ for 7 days. After this, medium, hydrogel and agar gel were removed and the toxicity of each sample was quantified by the addition of $250 \mu 1$ of 3 [4,5-dimethylthiazol-2-yl]-2,5-diphenyltetrazolium bromide (MTT, Sigma-Aldrich, USA) solution in PBS $\left(0.5 \mathrm{mg} \mathrm{ml}^{-1}\right)$ to each well. After $4 \mathrm{~h}$, the purple formazan crystals were dissolved in isopropanol ( $250 \mu \mathrm{l}$, Merck, Germany) by incubating at $37^{\circ} \mathrm{C}$ for $15 \mathrm{~min}$. The absorbance of each well was measured via a multiwell UV-Visible spectrometer (Shimadzu, model 1601) at $575 \mathrm{~nm}$ and normalized by the control measurement.

\subsection{Determination of glycosaminoglycan $(G A G)$ expression}

Dimethyl methylene blue (DMMB, Sigma-Aldrich, USA) was used for the quantification of GAGs expressed by the encapsulated chondrocyte according to a previously reported procedure [31]. Cells $\left(3 \times 10^{4}\right.$, after 14 days of isolation and $2^{\text {nd }}$ passage) were encapsulated and cultured in $1 \mathrm{ml}$ of culture medium for 14 days by adding another $1 \mathrm{ml}$ of the medium at day 7. The amount of $500 \mu \mathrm{l}$ of the medium of each well was added to $1.5 \mathrm{ml}$ of ice-cold acetone (Merck, Germany) and stored at $-20^{\circ} \mathrm{C}$ for $24 \mathrm{~h}$. The samples were centrifuged at $1800 \mathrm{rpm}, 4^{\circ} \mathrm{C}$ for $30 \mathrm{~min}$. The supernatant was removed and a papain solution $\left(20 \mu \mathrm{g} \mathrm{ml}^{-1}\right)$ activated with cysteine $(5 \mathrm{mM})$ was added. The mixture was maintained at $60^{\circ} \mathrm{C}$ for $16 \mathrm{~h}$ and boiled for $15 \mathrm{~min}$. The presence of GAGs in each sample was revealed by the addition of the DMMB reagent. The optical density was immediately measured at $545 \mathrm{~nm}$ using a microplate reader (Awareness Technologies, model Stat Fax 2100, USA). A working range of a known concentration of chondroitin sulphate $\mathrm{C}$ ( shark cartilage extract, Sigma-Aldrich, USA) was used as the standard solution.

\section{Results and discussion}

\subsection{Synthesis and characterization of hydrogels}

PEGIs were synthesized from the polycondensation reaction of PEG with different molecular weights (1000, 4000 and $8000 \mathrm{~g} \mathrm{~mol}^{-1}$ ) and IC (figure 1a). The polyesterification reaction was studied by FTIR spectroscopy (figure $2 \mathrm{a}$ ). The peaks at 1728 and $1098 \mathrm{~cm}^{-1}$ for PEGI1000 confirmed the formation of ester bonds between PEG and IC [33]. In addition, the peak at $1644 \mathrm{~cm}^{-1}$ showed the presence of the double bond in the structure of PEGI1000. The molecular structure of the synthesized PEGIs was completely investigated via NMR spectroscopy (figure $2 b$ ). The protons of the methylene $\left(\mathrm{CH}_{2}\right)$ group belong to the double bond appeared as two peaks at 5.6 and $6.2 \mathrm{ppm}$. The peaks at 3.2 and 3.4-3.6 ppm 
(a)<smiles>C=C(CC(=O)Cl)C(=O)Cl</smiles>

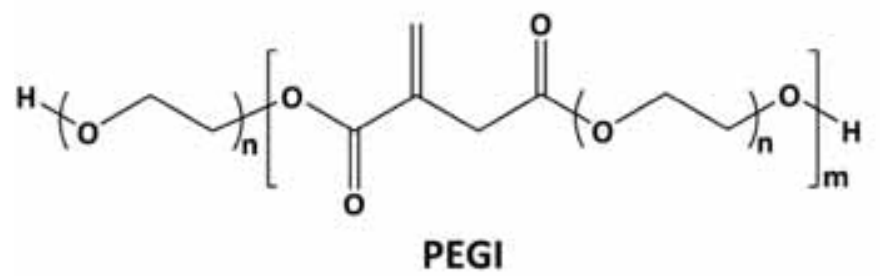

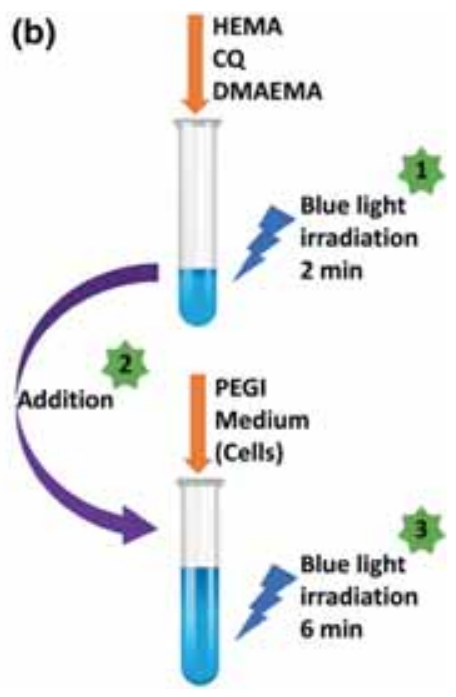

Figure 1. (a) Reaction pathway for the synthesis of PEGI. (b) Preparation procedure of cell encapsulated PEGI hydrogel.

(a)

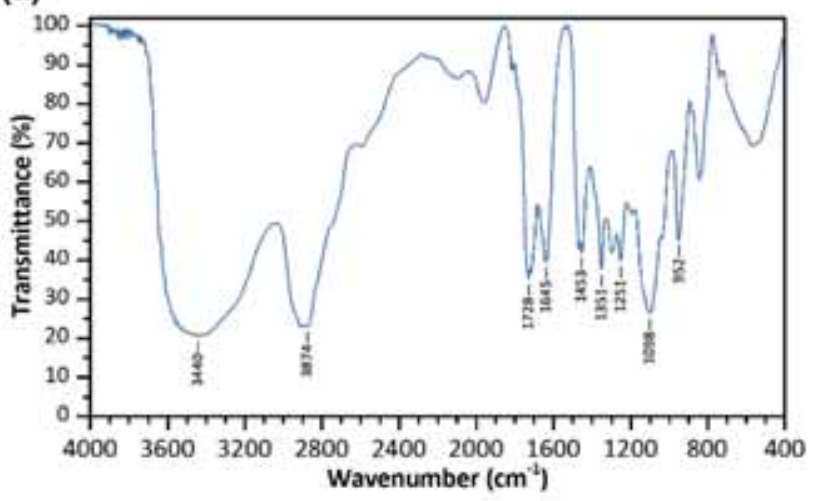

(b)

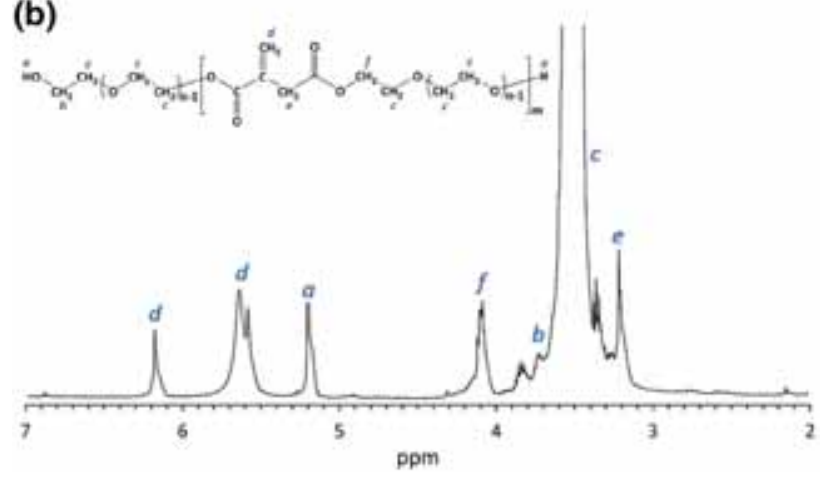

Figure 2. (a) FTIR and (b) ${ }^{1} \mathrm{H}-\mathrm{NMR}$ spectra of PEG1000.

were related to the methylene portions within IC and PEG moieties, respectively [34]. The average molecular weights of PEGI1000, PEGI4000 and PEGI8000 were 1400, 4500 and $8800 \mathrm{~g} \mathrm{~mol}^{-1}$, respectively.

For the preparation of hydrogels, HEMA was used as a reactive diluent and CQ/DMAEMA as a reactive photoinitiator system. HEMA-based polymers have been well established as biomaterials for different clinical applications such as contact lens or bone cement $[35,36]$. Cytotoxicity evaluation of the aqueous extract of three different dental based materials showed the lowest toxicity for HEMA in comparison with glycerol dimethacrylate and triethylene glycol dimethacrylate [37]. The inhibitory effect of water at low concentrations $(<5 \%)$ on CQ/DMAEMA has been reported previously [38]. However, this problem can be solved by the addition of aqueous part (culture medium and cells) after the activation of the photoinitiator system. For this purpose, the HEMA-CQ-DMAEMA solution was initially pre-cured via irradiating by blue light for 2 min and then the PEGI-DMEM solution (with or without the cells) was added followed by irradiation for 6 min (figure 1b). Another advantage for the pre-curing treatment is the reduction in cell toxicity risks emerged from the CQ/DMAEMA system. Several studies examined the hazardous effects of this system on the generation of reactive oxygen species and oxidative DNA damage [39]. It was proposed that oxidative DNA damage produced by the irradiated $\mathrm{CQ} /$ tertiary amine system could be significantly diminished by employing antioxidant substances such as glutathione and $N$-acetyl-L-cysteine [40].

The results of the curing test indicated unsuccessful curing of the $\mathrm{H} 1, \mathrm{H} 2, \mathrm{H} 4$ and $\mathrm{H} 7$ formulations. Moreover, increasing the amount of the initiator/activator improved the compression strength of the hydrogels (table 2). Although the number of free radicals increases at higher initiator/activator concentrations, some of them participate in a self-reacting process instead of the crosslinking reaction. These unreacted chemicals may leach out from the hydrogels and affect the biocompatibility of the final implant. Therefore, from the cytotoxicity viewpoint, these concentrations should be optimized to the lowest range. Conversely, no gelation was observed at a lower amount of the initiator/activator (the ratio of CQ/DMAEM to HEMA was $0.05 \%$ ) even at a longer curing time. The surplus amount of the initiator leads to the 
Table 2. Physical and mechanical properties of the hydrogels.

\begin{tabular}{|c|c|c|c|c|c|c|c|}
\hline Sample & $\begin{array}{l}\text { Gel time } \\
\text { (min) }\end{array}$ & $\begin{array}{c}\text { Gel yield } \\
(\%)\end{array}$ & $\begin{array}{c}\text { Water uptake } \\
\qquad(\%)\end{array}$ & $\begin{array}{c}\text { Gel yield } \\
(\%)\end{array}$ & $\begin{array}{l}\text { Degradation } \\
\text { after } 3 \text { months } \\
(\%)\end{array}$ & $\begin{array}{c}\text { Compressive } \\
\text { strength } \\
(\mathrm{MPa})\end{array}$ & $\begin{array}{c}\text { Elongation } \\
(\%)\end{array}$ \\
\hline H1 & $>30$ & - & - & - & - & - & - \\
\hline $\mathrm{H} 2$ & $>30$ & - & - & - & - & - & - \\
\hline H3 & 13 & 63.5 & $114 \pm 6$ & 58.3 & 5.2 & 0.98 & 8.4 \\
\hline $\mathrm{H} 4$ & $>30$ & - & - & - & - & - & - \\
\hline H5 & 4 & 86.5 & $102 \pm 9$ & 76.6 & 9.9 & 11.2 & 9.1 \\
\hline H6 & 3.5 & 91.8 & $108 \pm 4$ & 81.1 & 10.7 & 9.6 & 10.4 \\
\hline $\mathrm{H} 7$ & $>30$ & - & - & - & - & - & - \\
\hline H8 & 4 & 84.7 & $87 \pm 11$ & 77.0 & 7.7 & 10.4 & 11.5 \\
\hline H9 & 3 & 89.0 & $90 \pm 5$ & 81.4 & 7.6 & 8.5 & 11.8 \\
\hline H10 & 3 & 69.6 & $108 \pm 7$ & 59.2 & 10.4 & 24.1 & 23.7 \\
\hline H11 & 2.5 & 81.5 & $96 \pm 4$ & 78.3 & 3.2 & 39.8 & 50 \\
\hline H12 & 2.5 & 83.4 & $87 \pm 6$ & 79.7 & 3.7 & 26.5 & 46.25 \\
\hline H13 & 6 & 61.2 & $108 \pm 6$ & 37.1 & 24.1 & 2.51 & 3.3 \\
\hline H14 & 1.5 & 64.6 & $76 \pm 5$ & 59.8 & 4.8 & 23.1 & 42.8 \\
\hline
\end{tabular}
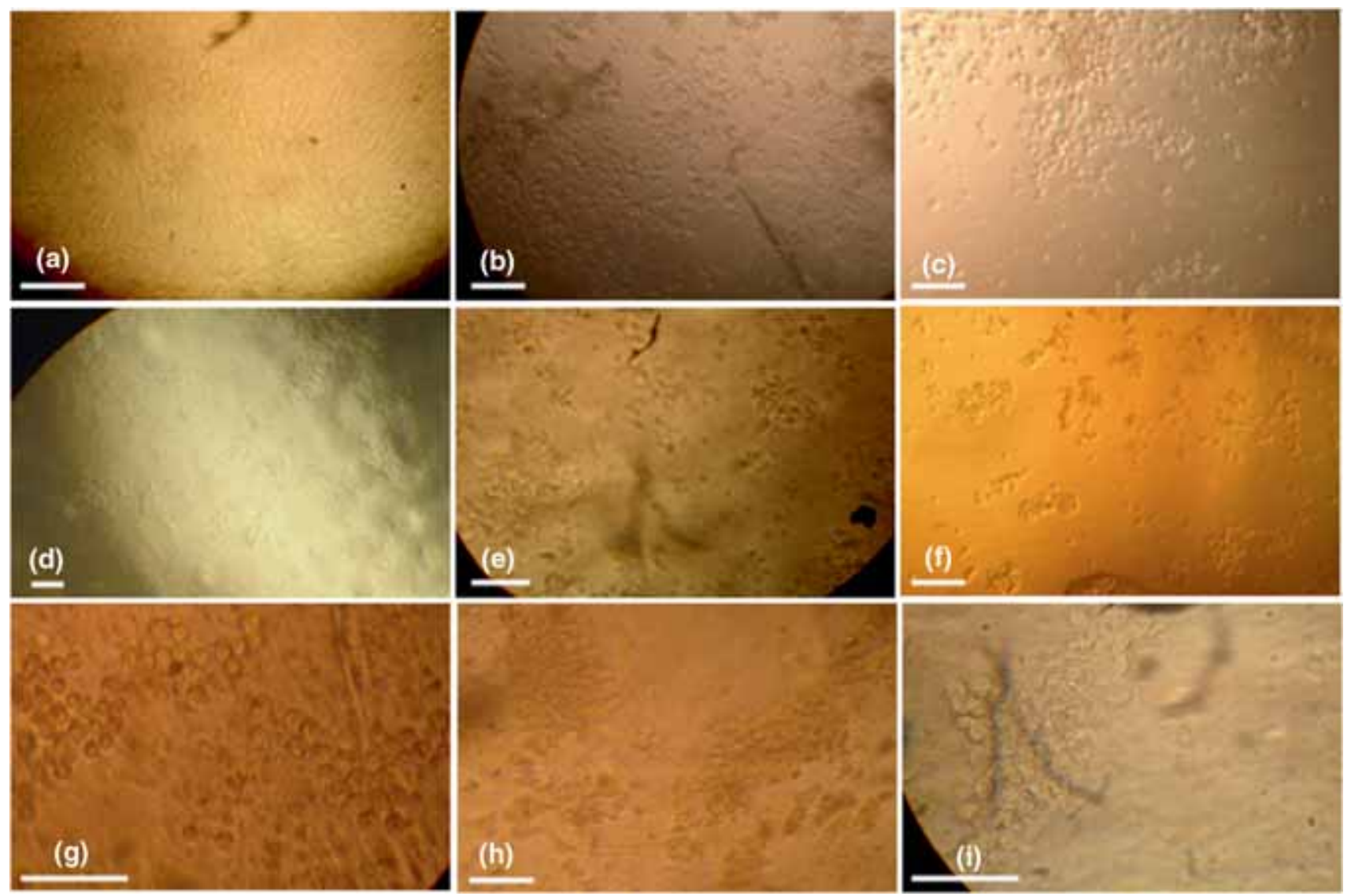

Figure 3. Rabbit chondrocytes encapsulated in different PEGI hydrogels: The cells cultured on the tissue culture plate as (a) control, (b, g) H3, (c, h) H5, (d, i) H8, (e) H13 and (f) H14. The bars are $20 \mu \mathrm{m}$.

stabilization of free radicals before activation of double bonds. This raises the chance for remaining unreacted residues which may act as a plasticizer [41]. In this investigation, samples H6,
H9 and H12 with the extra quantity of CQ demonstrated lower strength than their corresponding samples H5, H8 and H11, respectively. 

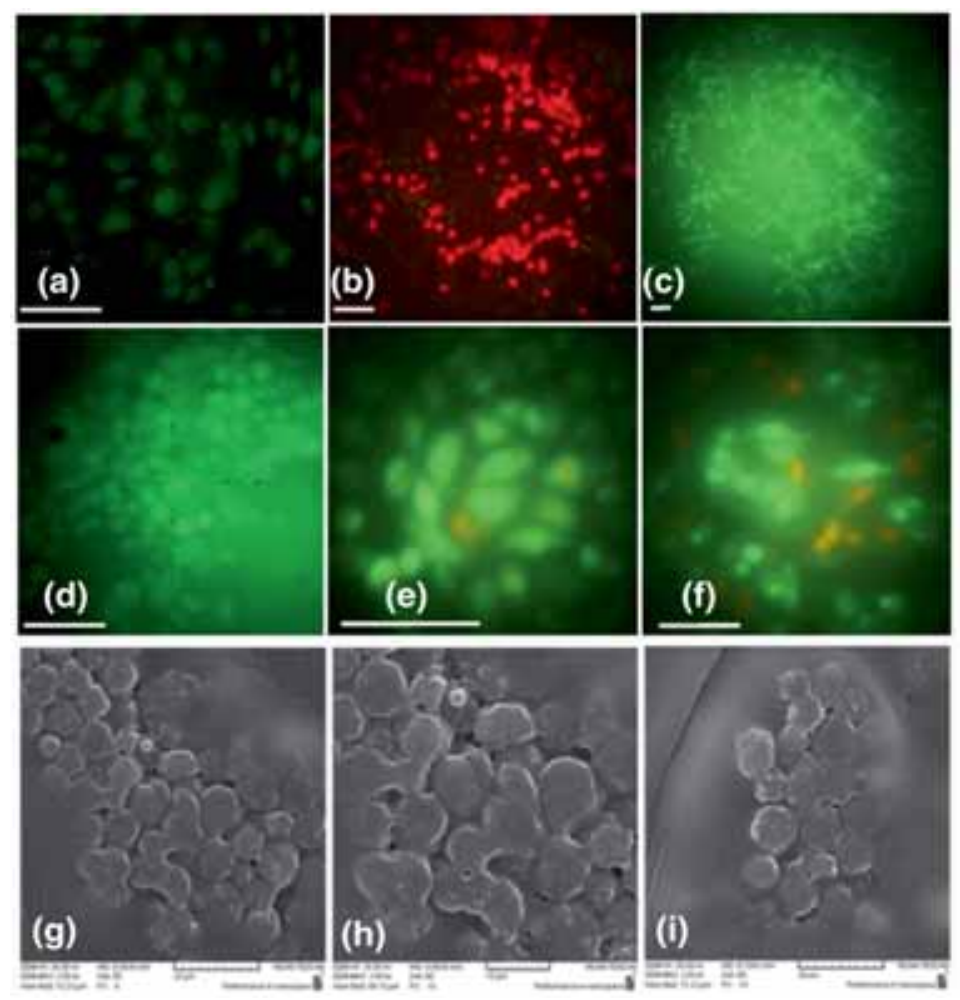
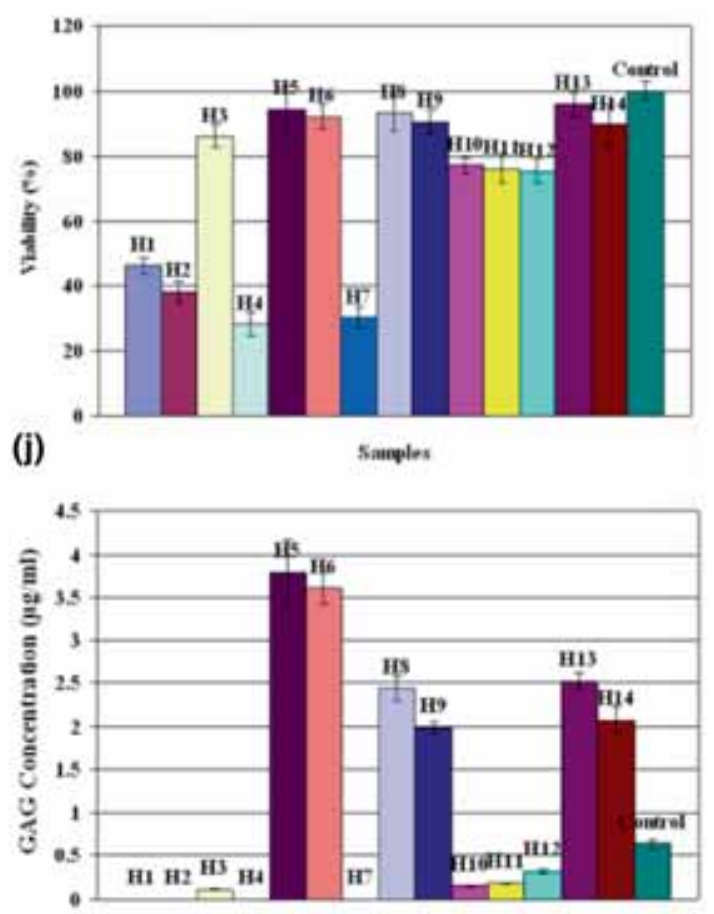

(k)

Samples

Figure 4. Live/dead assay with AO/PI staining of samples: (a) negative control, (b) positive control, (c) H3, (d) H5, (e) H10 and (f) H12. The bars are $20 \mu \mathrm{m}$. SEM images of (g) H3, (h) H5 and (i) H13. (j) The viability of isolated chondrocytes using agar diffusion assay after 7 days culture. (k) Quantification of GAG released from encapsulated chondrocytes in different hydrogels.

The viscosity and opacity of the formulations were increased during the light-curing process. A higher amount of CQ/DMAEMA resulted in faster gelation. The yield of gelation for $\mathrm{H} 6, \mathrm{H} 7, \mathrm{H} 9$ and $\mathrm{H} 10$ was more than $80 \%$ (table 2). It seems that the longer curing time and higher amount of HEMA are required to complete the gelation of PEGI1000 based hydrogels. The incorporation of PEGIs decreased the compression strength of the hydrogels. The lower molecular weight of PEGI1000 chains, in comparison with PEGI4000 and PEG8000, reduced the compression strength of the final products (table 2). From the other point of view, entanglement in PEGI4000 and PEG8000 maintained the longer chains in the structure after washing and swelling processes. Samples based on PEGI8000 showed higher elongation at break and lower compressive strength compared to the corresponding PEGI4000-based samples. The presence of water molecules in PEGI solution acts as a retardant for the crosslinking reaction [38]. Therefore, the highest compression strength and elongation were obtained in the absence of PEGIs.

In the next step, the ratio of HEMA to PEGI4000 was altered (H5, H3 and H14). The compressive strength of the samples was improved with increasing the amount of HEMA. In contrast, the absorption of equilibrium water decreased with increasing the amount of HEMA. However, due to the cytotoxicity of HEMA, the lowest possible amount of HEMA is preferable.

\subsection{Cell encapsulation in hydrogels}

The photomicrographs of the viable rabbit chondrocytes encapsulated in PEGI hydrogels (H3, H5, H8, H13 and H14) are depicted in figure 3. The spherical morphology of these cells at the first week of isolation after culturing on tissue culture polystyrene plate (TCPS) is shown in figure 3a.

The live and dead cells encapsulated in PEGI hydrogels after AO/PI staining are shown in figure $4 \mathrm{a}-\mathrm{f}$. The scanning electron micrographs of the isolated rabbit chondrocytes encapsulated in different samples are observed in figure $4 \mathrm{~g}-\mathrm{i}$. The morphology of chondrocytes in these samples was spherical, where chondrocyte-specific phenotype maintained. Figure $4 \mathrm{j}$ displays the results of the cytotoxicity assay in comparison with the control. This chart demonstrated that $\mathrm{H} 3, \mathrm{H} 5$, $\mathrm{H} 6, \mathrm{H} 8, \mathrm{H} 9, \mathrm{H} 13$ and $\mathrm{H} 14$ have cell viability more than $80 \%$. The exposure of the cells to hydrogel extracts revealed that the toxicity is increased using a higher amount of HEMA. Furthermore, elimination of PEGI in the samples (H10, H11 and $\mathrm{H} 12$ ) increases the toxicity of the specimens. H5, H8 and H13 with the lowest amount of HEMA showed lower cytotoxicity compared to the other samples. Figure $4 \mathrm{k}$ shows the comparison of GAG released from rabbit chondrocytes after 14 days of encapsulation. H5 and H6 represented a higher amount of GAG expression and confirm the positive influence on chondrocyte proliferation in comparison with control (TCPS) and other samples. 


\section{Conclusion}

In this study, PEGIs were synthesized and used in the formulation of photocurable hydrogels using the CQ/ DMAEMA system as a photoinitiator and HEMA as a reactive diluent. The physical, chemical and biological properties of the hydrogels were characterized and optimized for cell encapsulation. The hydrogel based on PEG4000 with a gel yield of $86 \%$, a water uptake of $103 \%$, a compressive modulus of 11.2 MPa, an elongation at a break of $9 \%$ and a curing time of 4 min was selected for the encapsulation of rabbit articular chondrocyte cells. The viability of encapsulated chondrocytes was evaluated by MTT and live/dead assays and the cell morphology was visualized by SEM. Moreover, the function of the encapsulated chondrocytes was determined by quantification of proteoglycan release. The results revealed that this hydrogel can be utilized as a scaffold for articular cartilage regeneration. Future investigations were conducted on stem cell differentiation and in animals.

\section{Acknowledgements}

The authors would like to express their appreciation to Pasteur Institute for their financial assistance. This study was supported by the research projects No. 370 and 498 .

\section{References}

[1] Zhang Y, Cai X, Yao J, Xing W, Wang L and Xia Y 2014 Angew. Chem. Int. Ed. 53184

[2] Hoffman A 2012 Adv. Drug. Deliv. Rev. 6418

[3] Nguyen K and West J 2002 Biomaterials 234307

[4] Burkoth A and Anseth K 2000 Biomaterials 212395

[5] Elisseeff J, Anseth K, Sims D, McIntosh W, Randolph M and Langer R 1999 Proc. Natl. Acad. Sci. USA 963104

[6] Koushki N, Katbab A, Tavassoli H, Jahanbakhsh A, Majidi M and Bonakdar S 2015 RSC Adv. 59089

[7] Slaughter B, Khurshid S, Fisher O, Khademhosseini A and Peppas N 2009 Adv. Mater. 213307

[8] Kinard L, Kasper F and Mikos A 2012 Nat. Protoc. 71219

[9] Benoit D, Schwartz M, Durney A and Anseth K 2008 Nat. Mater. 7816

[10] Escudero-Castellanos A, Ocampo-García B, DomínguezGarcía M, Flores-Estrada J and Flores-Merino M 2016 J. Mater. Sci. Mater. Med. 27176

[11] Sharifi S, Imani M, Mirzadeh H, Atai M, Ziaee F and Bakhshi R 2009 J. Biomed. Mater. Res. A 90830

[12] Bryant S and Anseth K 2002 J. Biomed. Mater. Res. A 5963

[13] Yang F, Williams C G, Wang D, Lee H, Manson P and Elisseeff J 2005 Biomaterials 265991
[14] Sharifi S, Mirzadeh H, Imani M, Ziaee F, Tajabadi M, Jamshidi A et al 2008 Polym. Adv. Technol. 191828

[15] Ifkovits J and Burdick J 2007 J. Tissue Eng. Regen. Med. 132369

[16] Hatefi A and Amsden B 2002 J. Control. Release 809

[17] Zada A, Avny Y and Zilkha A 1999 Eur. Polym. J. 351159

[18] Shete A U, El-Zaatari B, French J M and Kloxin C 2016 Chem. Commun. (Camb) $\mathbf{5 2} 10574$

[19] Lima G, Ogliari F, Souza e Silva M, Münchow E, Petzhold C and Piva E 2013 J. Appl. Polym. Sci. 1274160

[20] Yu Q, Nauman S, Santerre J and Zhu S 2001 J. Appl. Polym. Sci. 821107

[21] Andrzejewska E, Lindén L and Rabek J 1998 Macromol. Chem. Phys. 199441

[22] Teshima W, Nomura Y, Tanaka N, Urabe H, Okazaki M and Nahara Y 2003 Biomaterials 242097

[23] Johnson L, DeForest C, Pendurti A, Anseth K and Bowman C 2010 ACS Appl. Mater. Interfaces 21963

[24] Holland T A, Tabata Y and Mikos A G 2005 J. Control. Release 101111

[25] Temenoff J S, Athanasiou K, Lebaron R and Mikos A $2002 \mathrm{~J}$. Biomed. Mater. Res. B Appl. Biomater. 59429

[26] Veronese F 2001 Biomaterials 22405

[27] Cruise G M, Scharp D S and Hubbell J 1998 Biomaterials 191287

[28] Betancourt T, Pardo J, Soo K and Peppas N A 2010 J. Biomed. Mater. Res. 93175

[29] Teijon C, Guerrero S, Olmo R, Teijon J and Blanco M 2009 J. Biomed. Mater. Res. B 91716

[30] Sharifi S, Shafieyan Y, Mirzadeh H, Bagheri-Khoulenjani S, Rabiee S, Imani M et al 2011 J. Biomed. Mater. Res. A 98257

[31] Mirahmadi F, Tafazzoli-Shadpour M, Shokrgozar M A and Bonakdar S 2013 Mater. Sci. Eng. C 334786

[32] Bonakdar S, Emami S H, Shokrgozar M A, Farhadi A, Ahmadi S A and Amanzadeh A 2010 Mater. Sci. Eng. C 30636

[33] Darvishi A, Zohuriaan-Mehr M J, Bagheri-Marandi G, Kabiri K, Bouhendi H and Bakhshi H 2013 Des. Monomers Polym. 1679

[34] Okino H, Nakayama Y, Tanaka M and Matsuda T 2002 J. Biomed. Mater. Res. B Appl. Biomater. 59233

[35] Nogueira N, Conde O, Minones M, Trillo J and Minones J 2012 J. Colloid Interface Sci. $\mathbf{3 8 5} 202$

[36] Bircher A, Friederich N F, Seelig W and Scherer K 2012 Contact Dermat. 6620

[37] Becher R, Kopperud H, Al R H, Samuelsen J, Morisbak E, Dahlman H J et al 2006 Dent. Mater. 22630

[38] Wang Y, Spencer P, Yao X and Ye Q 2006 J. Biomed. Mater. Res. A 78721

[39] Atsumi T, Iwakura I, Fujisawa S and Ueha T 2001 Arch. Oral. Biol. 46391

[40] Winter K, Pagoria D and Geurtsen W 2005 Biomaterials 265321

[41] Arima T, Hamada T and McCabe J 1995 J. Dent. Res. 741597 